A s i a $\mathrm{n}$ o u r n a l of

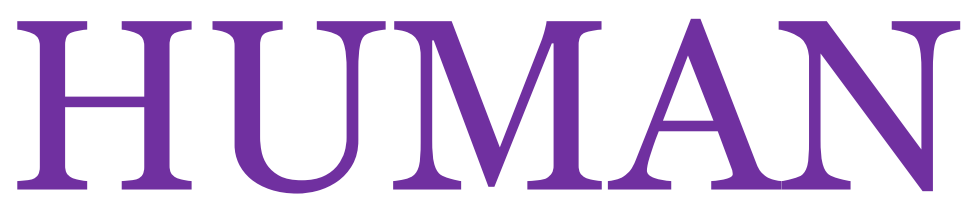

Printed 2019.0430 ISSN2188-059X

Published by Asian Society of Human Services
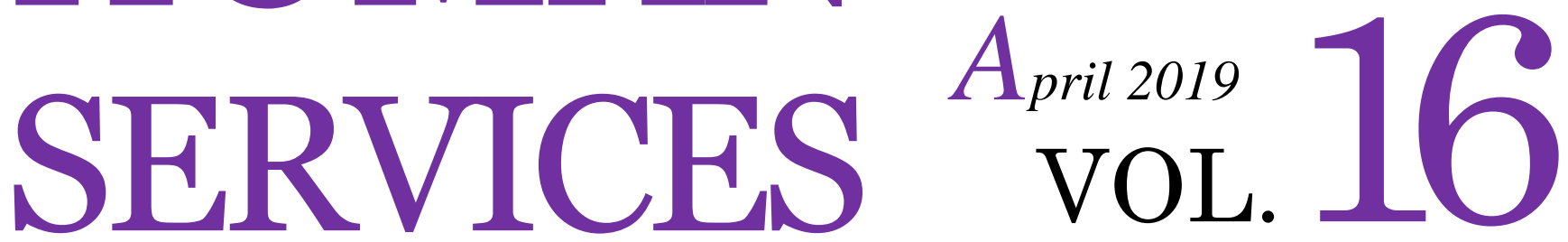

Snytax

Interpersonal relations

Education program

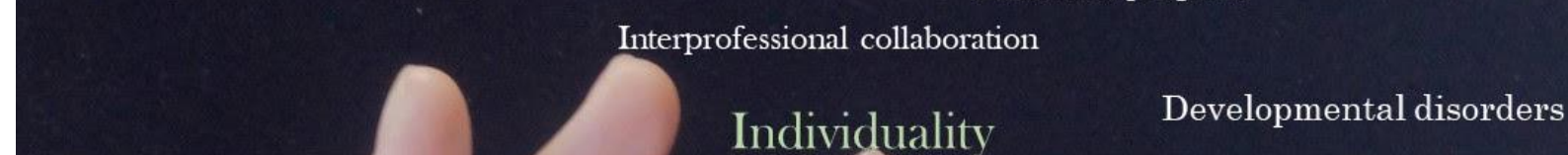

Individuality

Developmental disorders

Intellectual disabilities

Functional recovery care $\quad$ ICT program

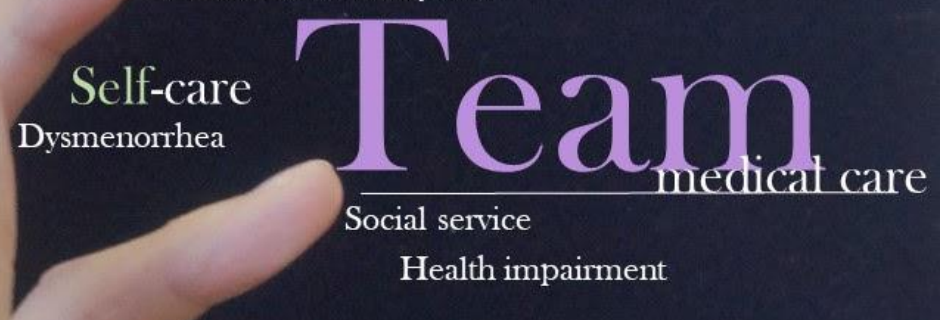

IN-Child Record (Inclusive Needs Child)

International Comparison

Empathy 


\title{
Services \\ Original Article \\ Investigating the Mediating Effect of Switching Barriers in the Relationship Between Social Service Quality and Switching Intention
}

\section{Sunhee KIM 1)}

1) Research Associate, Busan Welfare Call Network, Korea

\begin{abstract}
The present study investigated the mediating effect of switching barriers in the relationship between social service quality and switching intention for social service users. The purpose of this study is to provide baseline data on lowering switching intention by increasing social service quality, in order to promote policies and stable organizational management of service provider agencies. To this end, social service users in Busan were surveyed; 719 survey responses were used in the final analysis. The main results are as follows. First, social service users showed lower switching intention with higher perceived service quality. Second, higher switching barriers resulted in lower switching intention. Third, switching barriers in social services were found to mediate the effect of service quality on switching intention. Based on these results, implications regarding the reduction of switching intention that contributes to the success of social services are provided.
\end{abstract}

$<$ Key-words $>$

social service, service quality, switching barriers, switching intention

Received

March 28, 2019

Revised

April 18, 2019

Accepted

April 19, 2019

Published

April 30, 2019 pknukshr@hanmail.net (Sunhee KIM; Korea) Asian J Human Services, 2019, 16:87-100. ㅇ 2019 Asian Society of Human Services 


\section{Introduction}

Social services in South Korea have expanded since the 2000s with the introduction of the user-centered electronic voucher system, as universal services were pursued in preparation against new social risks across the society. From 2012, social service provider licenses became attainable under a registration system, allowing various agencies to provide social services. While this change to a user-centered method of provision led to a quantitative expansion of provider agencies through market competition, it has also brought endless controversy over service quality_including the content and price difference of social services and the qualification of provider agency professionals (Kim, 2009).

Service agencies also acknowledge user-perceived service quality as a major determinant in securing their competitiveness (Oh, 2006). That is, improving service quality is being emphasized as an essential factor in the survival of such organizations (Grasso, 1994). The importance of service quality has incentivized various literature regarding service quality since the advent of social services. In addition to research regarding the factors constituting service quality, numerous studies are being conducted in relation to the success of social services, such as those on the relationship between service quality and satisfaction as well as service quality and loyalty, and the cause-and-effect relationship among service quality, satisfaction, and loyalty (Kim, 2017; Kim \& Jung, 2012).

While users who use and are satisfied with a service opt to reuse it or maintain a favorable attitude towards it, there are cases where users who are dissatisfied due to their needs and wants, despite excellent service quality, choose to defect. Additionally, there are cases where they switch as they become dissatisfied despite their initial satisfaction (Cho \& Kim, 2015). Such phenomena reflect the fact that user satisfaction of service quality does not increase retention rate. Therefore, one needs to focus on the fact that switching barriers, which refer to the effort required to switch, can be used to increase retention rate when aiming to directly hinder users defecting.

Switching barriers refer to the complication of switching to a new provider, thereby ensuring that users continue to stay with their current provider even if they are dissatisfied with it (Poter, 1980). Thus, managers of provider agencies need to consider the switching barriers established between the user and the provider agency with respect to the causes of switching behavior, in addition to user dissatisfaction. The efficient management of such reality can be regarded as an important strategy in operating a social service agency in the midst of fierce quality competition due to the increasing number of provider agencies. Accordingly, agencies need to secure their user base by raising satisfaction in service quality to maintain loyalty, as well as creating switching barriers to deter users' intention to switch to other agencies. From the agency's perspective, the user base is more than simply securing stable users; instead, it becomes 
a fundamental asset in ensuring continuous growth and development, as well as a competitive edge, by reducing costs, increasing relation efficiency, and acquiring new users by word-of-mouth.

Based on the above discussion, service quality and switching barriers can be deduced to be important factors in lowering switching intention even in the field of social services where users have the right of choice. Therefore, within the field of social services, investigation of the mediating effect among the interest in switching barriers, service quality, and switching intention is highly significant both theoretically and practically. This study is conducted on social service users with respect to the effect of the quality of service provided by agencies on switching intention, in order to provide practical implications in efficient organization management by understanding the relational structure among the variables caused by the mediating effect of switching barriers. This is because an action plan to improve service quality, raise switching barriers, and lower switching intention must be devised beforehand if policy efforts to improve service quality and manage social service performance are to be effective.

\section{Theoretical Background}

\section{Social Service Quality}

Social service quality can be defined as "user behavior after subjectively perceiving the process and result of service provision" (Jeon, 2006). Gronroos (1984) claimed that service quality is the result of the interaction between the service provider and the user, and is created by a type of user perception of an agency's services or its image-building (Maeng \& Shim, 2011). In other words, compared to the general quality of service that indicates the user's subjective attitude or judgment of the excellence of service, interaction between users and the quality of service during service provision is more emphasized in the social service area.

Service quality in various fields of human service mainly use an application of the process-centric SERVQUAL model developed by Parasuraman, Zeithaml and Berry (PZB). This has also been used in recent studies on social service quality, arranged into assurance, responsiveness, empathy, reliability, and tangibles, depending on the focus of the researcher (Kim \& Jung, 2009). Reflecting the nature of social services, Kim \& Jung (2009) used six dimensions by adding sociality, which emphasizes the protection of users' rights. Therefore, social service quality is defined as the subjective evaluation of service content and its competent delivery, and is examined from the dimensions of sociality, assurance, responsiveness, empathy, reliability, and tangibles after including the extra dimension of sociality. 


\section{Association among Relationship between Social Service Quality, Switching Barriers, and Switching Intention}

Social service agencies regard service quality as an important determinant (Cho, 2012) of stable organizational management as it determines the users' decision to reuse a service without defecting to other agencies. Furthermore, in the context of social services, where the users' right of choice is emphasized, it is important for provider agencies to improve the user-perceived switching barriers and switching intention. This is because in terms of performance, strategic responses are needed to retain their current users. Fornell (1992) proposed switching barriers as a defensive strategy for retaining current users. Switching barriers suggest that there are cases where users with low satisfaction or dissatisfaction tend to stay with their current provider and provider agency rather than switching to other providers or agencies (Jones \& Sasser, 1995).

Switching barriers are defined as all factors that hinder users or incur costs, such as effort and time, when switching their provider agency (Jones, Mothersbaugh \& Beatty, 2000). Thus, switching barriers refer to all obstacles that are present when users switch their provider agency. The deterrents in switching barriers can be divided into switching costs, attractiveness of alternatives, and interpersonal relationships (Kim, 2017; Han, Back \& Barrett, 2009). Ping (1993) claimed that higher switching barriers lead to higher retention and loyalty from users. Weiss \& Anderson (1992) found that if switching requires high costs and difficult processes, the decision to switch becomes extremely slow even if one is dissatisfied, and in some cases, may lead to the continuation of the relationship (Jackson, 1985). The role of switching barriers is to deter users from switching provider agencies by influencing their switching intention through high costs of time and effort when switching, or by having unattractive alternatives for competition. Switching barriers are defined in this study as all deterrents in defecting or switching from the current service agency, comprised of the objective situational variables of switching costs and lack of alternatives (a concept contrary to the attractiveness of alternatives).

Switching intention is a concept contrary to the retention of existing users and reuse intentions, and refers to the user's intention of switching from one service from another (Jones, Mothersbaugh \& Beatty, 2002). Furthermore, switching intention leads to a reduction in the number of existing users due to users switching services, and such switches are made based on the users' desire for something new due to their dissatisfaction with provided services (Jeon, Bang \& Ko, 2017; Keaveney, 1995). Service switches, switching intention, service loyalty, user retention, and reuse intention are all related (Han, Back \& Barrett, 2009). Loyalty, retention, and reuse intention are favorable outcomes for the provider, whereas service switches and switching intention are not. Stronger switching intention heightens the possibility that one carries out the switch, and conversely, that possibility is reduced with weaker switching intention (Bintner, Booms \& Tetreault, 1990). This study defines switching intention as the desire to defect 
from the current provider or provider agency and examines its relationship with service quality and switching barriers.

Reviewing the effect of service quality on switching intention based on the above discussion, Kim (2008) suggests that higher quality of educational service lowers the intention to switch schools. Lee \& Murphy (2005) brainstormed the causes of switches and discovered that service quality had the highest effect on switching behavior. Jones, Reynolds, Mothersbaugh, et al. (2007) found that the quality of educational services had a negative effect on switching intention. Such results can be interpreted as high-quality services provided by current agencies lowering user intention to switch to other agencies.

Literature on the relationship between switching barriers and switching intention shows that switching costs influence user behavior and behavioral intention. The literature proposed that switching barriers have a negative effect on switching intention (Liu, Park \& Kim, 2017; Cho \& Kim, 2015; Jones,Retnolds, Mothersbaugh, et al, 2007; Burnham, Frels \& Mahajan, 2003). This implies that provider agencies should raise switching barriers to make users reuse their services without switching. In a social service study on the moderating role of switching barriers in the relationship between relational quality and loyalty, Kim (2017) claimed that higher switching costs and fewer competitive alternatives raise switching barriers and thereby increase loyalty.

Finally, regarding previous studies on the mediating effect of switching barriers between service quality and switching intention, Jones, Mothersbaugh \& Beatty (2002) found that service quality is deeply related with switching costs upon empirical analysis. Cha (2007) verified that service quality has a strong influence on switching barriers. Moreover, by examining service quality in the categories of functional quality and technical quality, Byeon (2009) found that switching barriers mediate the relationship between service quality (functional and technical) and switching intention. That is, users perceive switching barriers (the high cost of switching and the lack of competitive alternatives) to be higher with increased quality of service, which leads to lower switching intention and ultimately their decision to remain with their current agency.

The relationship between major variables used in this study were examined in various service areas throughout the literature. It can be seen that switching barriers, which make user switches to other service agencies more difficult, are affected by service quality and related to switching intention. Therefore, this study examines indirect paths in the relational structure among service quality, switching barriers, and switching intention, in order to determine the cause-and-effect therein. This is because it is significant to investigate the role of switching barriers in the above relationship to improve the performance of agencies, even in the context of social services which are provided in a user-centric manner. 


\section{Research Method}

\section{Research Model and Hypotheses}

The research model was set as seen in $<$ Figure $1>$ in accordance with the purpose of this study of examining the effect of social service quality on switching intention with switching barriers as its mediator.

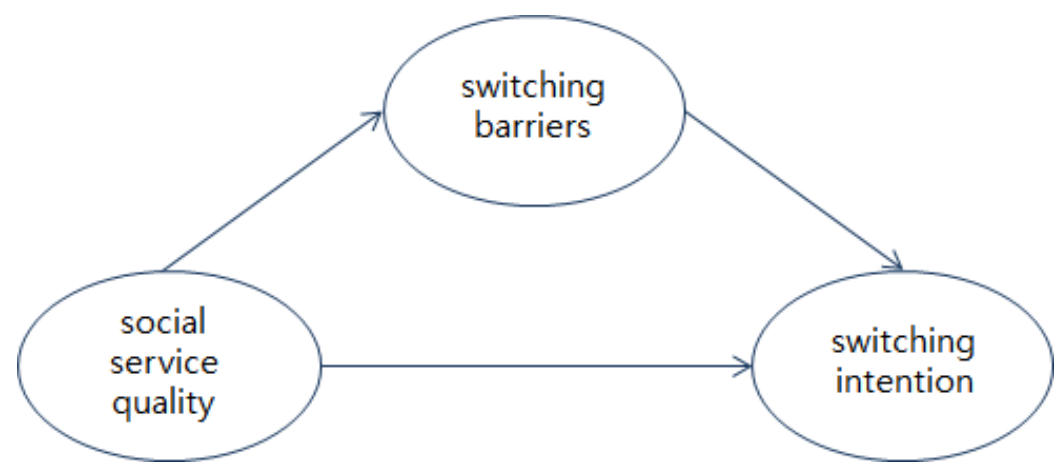

$<$ Figure 1 $>$ Research Model

The hypotheses derived from the research model are as follows.

Hypothesis 1 . Social service quality will affect switching intention.

Hypothesis 2. Switching barriers will affect switching intention.

Hypothesis 3. Social service quality will affect switching intention, mediated by switching barriers.

\section{Research Subjects and Data Collection}

The subjects of the present study consisted of Busan residents who use the Long-term Care Service for the Elderly, Personal Assistance Service for the Disabled, and Psychological Support Service for Children and Youth, all of which are implemented nationwide, use a standardized manual for delivery and business content, and are provided to a distinct group of users. The Long-term Care Service for the Elderly and the Psychological Support Service for Children and Youth were stratified according to region and significantly allocated based on the method of provision. Personal Assistance Service for the Disabled, managed only by nonprofit organizations, was proportionally allocated according to region and selected through random sampling. Trained researchers, as well as managers and providers at service provider agencies, delivered the questionnaires and asked for participation. The questionnaire was approved by the Research Ethics Committee and was administered after a research participation consent form was submitted by the respondent. Data collection took place from November 2015 to February 2016, during which 756 questionnaires from the 1,050 delivered to research subjects were 
collected. In total, 719 questionnaires were used in the actual analysis after excluding those that were filled in dishonestly.

\section{Variables and Measures}

The latent variables of this study consist of social service quality, switching barriers, and switching intention. The scale used by Kim \& Jong (2012) was used to measure service quality, and the scale used by Whang \& Chang (2007) was used to measure switching barriers (switching costs and lack of alternatives) after it was modified and supplemented. For switching intention, the scale used by Oh \& Lee (2014) for public library visitors was modified to conform to social services, and was used to survey "the possibility of not using the current center" and "collecting information on new centers to transfer to." All items were measured via a 5-point Likert scale (strongly disagree $=1$ point, strongly agree $=5$ points). Therefore, higher quality of service leads to a higher perception of switching barriers (higher switching costs and fewer competitive alternatives), thereby lowering switching intention. The levels of confidence among the variables measured in this study were found to be appropriate at $\mathrm{a}=.896$ for social service quality, $\mathrm{a}=.835$ for switching barriers, and $\mathrm{a}=.882$ for switching intention.

\section{Analysing Methods}

SPSS 22.0 and Amos 22.0 were used to analyze the cause-and-effect relationship and mediating effect of the research model and to examine their statistical significance. GFI and RMSEA were used for $\chi^{2}$ statistics and absolute index of fit, and CFI and TLI were comprehensively considered for the normed fit index. Smaller RMSEA values indicate a better fit, and a value of .05 or below is deemed to be of good fit. A value of .09 or above is deemed a good fit for CFI, TLI, and GFI. Structural equation modeling was conducted to verify the research hypotheses, and bootstrapping was conducted to examine the significance of the indirect effect of switching barriers used as the mediating variable.

\section{Results}

\section{Sociodemographic Characteristics among Research Subjects}

The sociodemographic characteristics of the subjects of this study are shown in <Table $1>$. Respondents evenly varied in age from children to the elderly and handicapped. For the duration of service usage under the current agency, most respondents were included in the category of 1 to 3 years at $38.9 \%$, followed by under 1 year at $29.1 \%$. There was an even distribution of for-profit $(46.9 \%)$ and non-profit $(61.1 \%)$ organizations. The characteristics of social service recipients were well reflected among the respondents. 
$<$ Table $1>$ Characteristics of the Participants

\begin{tabular}{lll}
\hline & Characteristic & $\mathrm{n}(\%)$ \\
\hline \multirow{2}{*}{ Respondent } & Self & $443(61.6)$ \\
Sex & Guardian & $276(38.4)$ \\
& Male & $398(55.4)$ \\
& Female & $321(44.6)$ \\
Age & Under 8 & $118(16.4)$ \\
& $8-13$ & $97(13.5)$ \\
& $14-20$ & $20(2.8)$ \\
& $21-49$ & $107(14.9)$ \\
Duration of usage & $50-65$ & $98(13.6)$ \\
under current agency & Over 66 & $279(38.9)$ \\
& Under 1 year & $209(29.1)$ \\
Type of organization & 1 to 3 years & $274(38.1)$ \\
& 5 years or more & $165(22.9)$ \\
& For-profit & $79(11.0)$ \\
& Non-profit & $337(46.9)$ \\
\hline
\end{tabular}

The following <Table $2>$ shows the descriptive statistics of the measured variables. Considering the conditions of normal distribution (skewness $<2$, kurtosis $<4$ ) in the structural equation modeling used in this study, all necessary conditions are met.

$<$ Table 2> Descriptive Statistics of Variables

\begin{tabular}{llllcc}
\hline & Latent variable & Mean & SD & Skewness & Kurtosis \\
\hline \multirow{4}{*}{ Social } & Sociality & 3.921 & .534 & -.770 & .147 \\
service & Essurance & 4.002 & .602 & -.620 & -.060 \\
quality & Responsiveness & 3.979 & .802 & -.849 & .057 \\
& Reliability & 4.078 & .459 & -1.001 & .187 \\
& Tangibles & 4.122 & .761 & -.861 & .157 \\
Switching & Switching costs & 3.123 & .534 & -.509 & -.638 \\
barriers & Lack of alternatives & 3.849 & .973 & -.881 & .128 \\
Switching & Switching intention 1 & 2.924 & .852 & .529 & -.181 \\
intention & Switching intention 2 & 3.235 & .742 & -1.290 & 1.005 \\
\hline
\end{tabular}

\section{Correlations Among Major Variables}

Correlation among the variables used to verify the cause-and-effect structure set for this study are displayed in <Table $3>$. Results show that the social service quality dimension has a statistically significant negative correlation to switching intention $(\mathrm{r}=-.306 \sim-.598, \mathrm{p}<.01)$, and a statistically significant positive correlation to switching barriers $(\mathrm{r}=.239 \sim .455, \mathrm{p}<.01)$. Switching intention shows a statistically significant negative correlation to switching barriers $(\mathrm{r}=.413 \sim .437, \mathrm{p}<.01)$. Therefore, this indicates that positive social service quality leads to a higher perception of switching barriers, and that higher switching barriers lead to decreased switching intention. 
$<$ Table $3>$ Correlations Among Major Variables

\begin{tabular}{|c|c|c|c|c|c|c|c|c|c|c|}
\hline & 1 & 2 & 3 & 4 & 5 & 6 & 7 & 8 & 9 & 10 \\
\hline 1. Sociality & 1 & & & & & & & & & \\
\hline 2. Assurance & $.467 * *$ & 1 & & & & & & & & \\
\hline 3. Empathy & $.490 * *$ & $.671^{* *}$ & 1 & & & & & & & \\
\hline 4. Responsiveness & $.335 * *$ & $.529 * *$ & $.541 * *$ & 1 & & & & & & \\
\hline 5. Reliability & $.461 * *$ & $.668 * *$ & $.576 * *$ & $.672 * *$ & 1 & & & & & \\
\hline 6. Tangibles & $.240 * *$ & $.263^{* *}$ & $.260 * *$ & $.216 * *$ & $.347 * *$ & 1 & & & & \\
\hline 7. Switching costs & $.314^{* *}$ & $.445^{* *}$ & $.419 * *$ & $.412^{* *}$ & $.455^{* *}$ & $.239^{* *}$ & 1 & & & \\
\hline 8. Lack of alternatives & $.335^{* *}$ & $.429 * *$ & $.411^{* *}$ & $.401 * *$ & $.422^{* *}$ & $.316^{* *}$ & $.535^{* *}$ & 1 & & \\
\hline 9. Switching intention 1 & $-.439 * *$ & $-.598 * *$ & $-.517 * *$ & $-.503^{* *}$ & $-.557 * *$ & $-.306^{* *}$ & $-.421 * *$ & $-.423 * *$ & 1 & \\
\hline 10. Switching intention 2 & $-.419 * *$ & $-.593^{* *}$ & $-.527 * *$ & $-.457 * *$ & $-.566^{* *}$ & $-.376^{* *}$ & $-.413 * *$ & $-.437 * *$ & $-.692^{* *}$ & 1 \\
\hline
\end{tabular}

${ }^{*} \mathrm{p}<.05,{ }^{*} \mathrm{p}<.01$

\section{Measurement Model Analysis}

The present study hypothesized that higher social service quality will lead to higher satisfaction in the agency and provider, and that higher perception of switching barriers will lead to decreased switching intention to defect to other agencies. The hypotheses were verified through structural equation modelling. Goodness of fit was found to be appropriate at a satisfactory level as shown in $<$ Table $4>$.

$<$ Table $4>$ Goodness of Fit

\begin{tabular}{ccccccc}
\hline & $\chi^{2}$ & $\mathrm{df}$ & GFI & CFI & TLI & RMSEA \\
\hline Model & 121.097 & 51 & .911 & .963 & .959 & .047 \\
\hline
\end{tabular}

With goodness of fit verified, the hypotheses of this study were examined through their path coefficients. The path from social service quality to switching intention was found to be statistically significant from the parameter estimates shown in $<$ Figure $2>$ and $<$ Table $5>$, showing higher quality of service leading to lower switching intention.

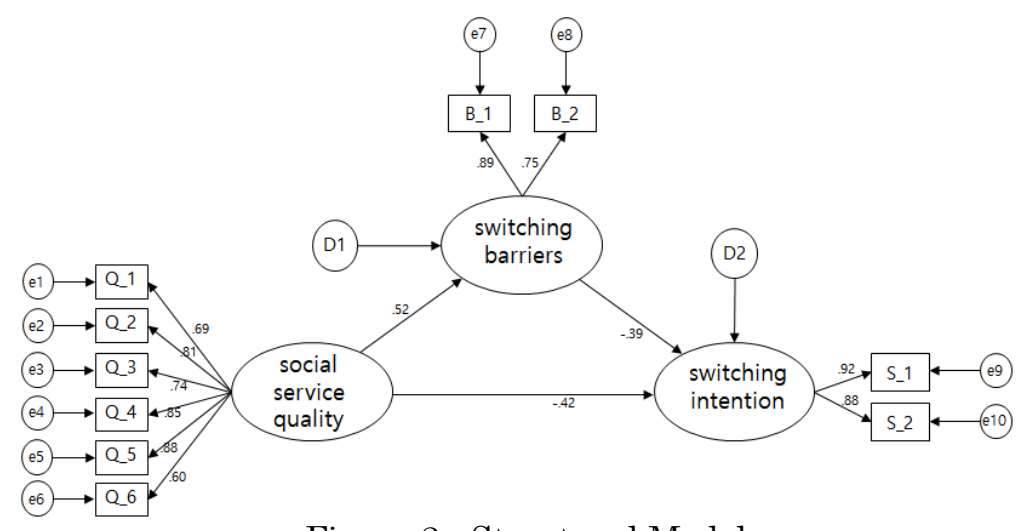

$<$ Figure 2> Structural Model

Q_1: Sociality, Q_2: Assurance, Q_3: Empathy, Q_4: Responsiveness, Q_5: Reliability,

Q_6: Tangibles, B_1: Switching costs, B_2: Lack of alternatives 
Furthermore, the path from service quality to switching barriers was found to be statistically significant. This indicates that higher service quality raises switching barriers. In other words, if users form a relationship of trust with the provider in the process of service provision and engages in more positive interactions, they feel uncomfortable with the costs of switching to a different agency and searching for alternatives, thereby increasing the switching barriers. The path from switching barriers to switching intention was also found to be statistically significant, and higher perception of switching barriers led to a decreased intention to switch or defect. Thus, both Hypothesis 1 and Hypothesis 2 were supported by the results.

$<$ Table 5> Path Coefficients of the Structural Model

\begin{tabular}{|c|c|c|}
\hline Path & $\mathrm{B}$ & B \\
\hline Social service quality --> Switching barriers & .613 & $.524^{* * *}$ \\
\hline Social service quality --> Switching intention & -.439 & $-.415^{* *}$ \\
\hline Switching barriers $\quad-->$ Switching intention & -.499 & $-.387 * *$ \\
\hline
\end{tabular}

${ }^{*} \mathrm{p}<.05, * * \mathrm{p}<.01, * * * \mathrm{p}<.001$

\section{Decomposition and Mediating Effect Analysis}

Results indicated that switching barriers mediate the connection between social service quality and switching intention. Bootstrapping was conducted to analyze the mediating effect and examine the influencing relationship among variables decomposed into direct and indirect effects. Decomposition results indicated that the total effect of social service quality on switching intention is -.618, consisting of both direct $(-.415)$ and indirect (-.203) effects, as shown in <Table 6>.

$<$ Table 6> Decomposition of Structural Model Variable

\begin{tabular}{llllll}
\hline Path & & $\begin{array}{l}\text { Total } \\
\text { effect }\end{array}$ & $\begin{array}{l}\text { Direct } \\
\text { effect }\end{array}$ & $\begin{array}{l}\text { Indirect } \\
\text { effect }\end{array}$ & $\begin{array}{l}\text { Confidence } \\
\text { interval }\end{array}$ \\
\hline $\begin{array}{l}\text { Social service quality } \\
\text { Switching intention }\end{array}$ & $->$ & & & & \\
\hline
\end{tabular}

$* \mathrm{p}<.05, * * \mathrm{p}<.01$

Bootstrapping the mediating effect of switching barriers resulted in a confidence interval of -.072 -.229, which shows that the mediating effect is statistically significant at a significance level of $\mathrm{p}<.01$, as a "0" is not included in its range. Therefore, switching barriers in social services were found to partially mediate the effect of service quality on switching intention. 


\section{Discussion}

The present study aimed to examine the relationship between social service users' switching intention and service quality, and to verify the mediating effect of switching barriers. To this end, 719 Busan residents using universal services in South Korea, the Long-term Care Service for the Elderly, Personal Assistance Service for the Disabled, and Psychological Support for Children and Youth, were selected for analysis. Analysis results using Amos 22.0 to study the research model and hypotheses are as follows.

First, social service quality was found to have a direct effect on switching intention. That is, improved quality of service from social service provider agencies and user optimism for service quality leads to a decrease in switching intention. Second, the switching intention of social service users was weakened with higher switching barriers. This indicates that the switching intention of service users is lowered with higher switching costs of effort, time, and money, and fewer competitive agencies that provide better quality alternatives than the current one. Third, social service quality was found to influence switching intention mediated by switching barriers. In other words, while service quality indeed has a direct effect on switching intention, higher service quality led to higher switching barriers, which in turn decreased switching intention. This result is in line with the literature (Byeon, 2009) that claims switching barriers are important in relation to service quality.

For agencies to perform well in the field of social services, where financial support is given on the basis of expanding users' right of choice, improvement of service quality by competition between agencies is important. To prevent user defects and switches, provider agencies must protect the rights of their users while increasing job and supplement training to better equip providers with professional knowledge, skills, and accountability to provide services in a safe environment.

Verification of the importance of switching barriers that affect service quality and switching intention is highly significant in relation to the performance of social service provider agencies. Success in social services was found to be mediated by switching barriers rather than being directly achieved through social service quality. Therefore, service quality and switching barriers were confirmed to be important influencing factors on switching intention. The switching barrier variable should be considered since the defection of users satisfied with service quality becomes more frequent especially for social service provider agencies that lack differentiation and are locked in fierce competition. As such, social service policies must recognize switching barriers, such as the psychological effort of switching, cost of finding alternatives, inconvenience, and lack of good alternatives, as an important factor at the stage of their design.

In addition to professional quality, providers and provider agencies must improve their service quality from a relational aspect with individual users as well if they are to enhance their switching barriers, the importance of which has been demonstrated in the 
area of social services. Providers must be trained for relational sensitivity to positively maintain the interaction between users and providers, which is a critical aspect in social service quality. If agencies are to provide services and relational benefits of higher value than their competitors, users will find costs in the time and psychological effort to switch to different agencies burdensome, perceive the current agency to be more attractive than competing ones, and weaken their switching intention. Thus, to minimize user defection, it is suggested that agencies strategically increase their switching barriers by enhancing relational quality and utilize switching barriers from all dimensions.

\section{References}

1) Kiryong KIM (2009) Current State and Future Agenda of Voucher Programs for Rehabilitative Therapy and Services for Children with Disabilities. Welfare Trends, $124,19-22$.

2) Changguen OH (2006) The Study of Social Welfare Center Service Evaluation Using the SERVQUAL Model. The Korean Association for Public Welfare Administration, 16(2), 199-226.

3) Anthony GRASSO (1994) Management Style, Job Satisfaction, and Service Effectiveness. Administration in Social Work, 18(4), 89-105.

4) Sunhee KIM (2017) The Moderating Effect of Switching Barriers in the Relationship Between Social Service Relationship Quality and Service Loyalty. Journal of Korean Social Welfare Administration, 19(1), 171-198.

5) Eunjeong KIM \& Euna JONG (2012) Quality Evaluation and Service Reuse Intention among the Service Users of Community Services Innovation: Focusing on the Early Intervention Service for Children with ADHD. Local Government Studies, 16(1), 331-352.

6) Eunah CHO \& Gun KIM (2015) A Study on Two Dimensions of Switching Barriers Affecting Switching Intention: Focus on Hotel Restaurant. Korean Journal of Tourism Research, 30(6), 239-261.

7) Michael PORTER (1980) Competitive strategy. Academic Press, New York.

8) Joongoo JEON (2006) The Causal Model of Service Quality, Clients Satisfaction, and Succeeding Behavior in Social Welfare Organization. Journal of Korean Social Welfare Administration, 8(2), 105-139.

9) Christian GRONROOS (1990) Service Management and Marketing: Managing the Truth in Service Competition, Lexington Books. Co.

10) Tuyul MAENG \& Yongmi SHIM (2011) A Study on the Influence of Welfare Service Quality for the Elderly and Customer's Satisfaction upon Intention of Re-use. Health and Social Welfare Review, 31(2), 180-205. 
11) Eunjeong KIM \& Souon JUNG (2009) The Association Between Dimensions of Social Service Quality and Service User's Satisfaction: Focused on Domiciliary Care Service for the Elderly. Social Welfare Police, 36(2), 191-217.

12) Sungsook CHO (2012) A Study on the Dynamics of the Quality, Satisfaction, and Reuse Intention of Community Social Services. Korean System Dynamics Society, 13(2), 73-91.

13) Claes FORNELL (1992) A national customer satisfaction barometer: the Swedish experience. Journal of Marketing, 56(1), 6-21.

14) Thomas JONES \& W. Earl SASSER (1995) Why Satisfied Customers Defect. Harvard Business Review, 73(6), 88-102.

15) Michael JONES, David MOTHERSBAUGH \& Susan BEATTY (2000) Switching Barriers and Repurchase Intentions in Services. Journal of Retailing, 76(2), 259-274.

16) Heesup HAN, KiJoon BACK \& Betsy BARRETT (2009) Influencing Factors on Restaurant Customers' Revisit Intention: The Roles of Emotions and Switching Barriers. International Journal of Hospitality Management, 28(4), 563-572.

17) Barbara JACKSON (1985) Build Customer Relationships That Last. Harvard Business Review, 63(6), 120-128.

18) Michael JONES, David MOTHERSBAUGH \& Sharon BEATTY (2002) Why Customers Stay: Measuring the Underlying Dimensions of Services Switching Costs and Managing Their 4 Differential Strategic Outcomes. Journal of Business Research, 55(6), 441-450.

19) Hongshin JEON, Hyojin BANG \& Kyoungsook KO (2017) The Effects of Educational Satisfaction on School Conversion Intention According to the Quality of University Education Service: Focusing on Beauty Departments. Journal of the Korea Fashion \& Costume Design Association, 19(1), 121-134.

20) Susan KEAYENEY (1995) An Exploratory Study. Journal of Marketing, 59(Apr), 71-82.

21) Mary Jo BINTNER, Bernard H. BOOMS, \& Mary Stanfield TETREAULT (1990) The Service Encounter: Diagnosing Favorable Incidents. Journal of Marketing, 55(1), 71-84.

22) Sungshik KIM (2008) An Exploratory Study on Withdrawal and Transfer of Korean College Students: The Influence of College Choice and Campus Life Satisfaction. Korean Educational Research Association, 35(1), 227-249.

23) Michael JONES, Kristy RETNOLDS, David MOTHERSBAUGH \& Susan BEATTY (2007) The Positive and Negative Effect of Switching Costs on Relational Outcomes. Journal of Service Research, 9(4), 335-355

24) Feng LIU, ChanKwon PARK \& ChaeBogk KIM (2017) Correlations Among Service Quality, Customer Satisfaction, Customer Loyalty, Switching Barrier, and Switching Intention in Mobile Communications. Journal of Business Research, 32(2), 27-68. 
25) Thomas BURNHAM, Judy FRELS \& Vijay MAHAJAN (2003) Consumer switching costs: a typology, antecedents, and consequences. Journal of the Academy of the Academy of Marketing Science, 31(2), 109-126.

26) Soonkwon CHA (2007) Empirical Study on Customer Loyalty of Foreign Electronic Business Transaction Website. Korea Trade Review, 32(4), 167-196.

27) Hyeonsu BYOEN (2009) The Influence of Technical Quality and Functional Quality on Switching Barriers. Korean Journal of Business Administration, 22(6), 3655-3672.

28) Inchang WHANG \& Wonhae CHANG (2007) The Effects of Medical Service Quality on the Relationship Quality and Service Loyalty: The Moderating Effects. Journal of Industrial Economics and Business, 20(5), 1875-1902

29) Yunjung OH \& Sungsook LEE (2014) Relations Among Public Library Service Quality, Relationship Quality, Intention to Revisit, and Intention to Shift. Journal of Social Science, 25(3), 33-55. 
- Editorial Board -

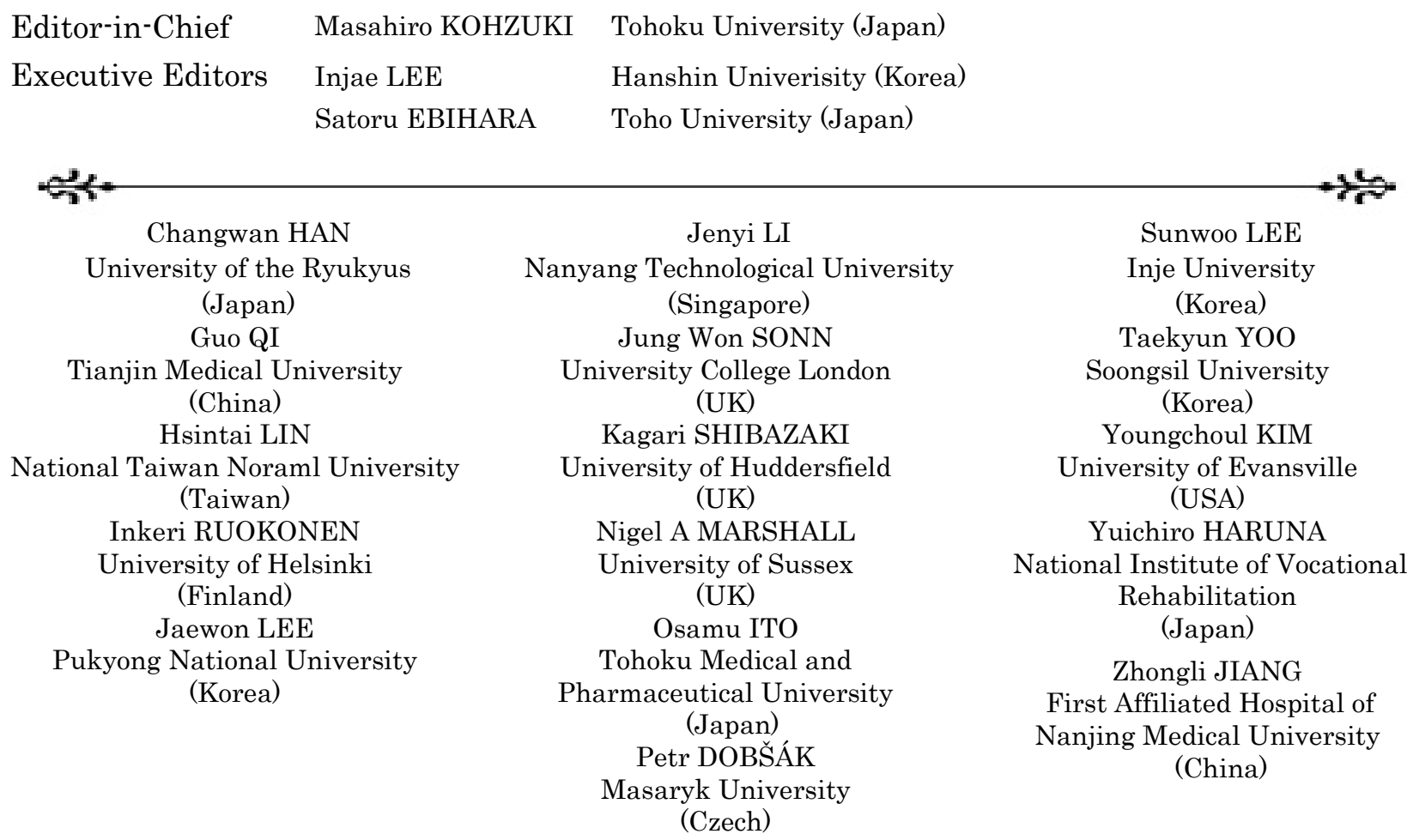

Editorial Staff

- Editorial

Assistants
Aiko KOHARA

Marcus Eije Zantere

Moonjung KIM
University of the Ryukyus (Japan)

University of Gothenburg (Sweden)

Korea Labor Force Development Institute for the aged (Korea)

Natsuki YANO

Tohoku University / Pasona-foster Inc. (Japan)

\section{Asian Journal of Human Services VOL.15 Ocober 2018}

(C) 2018 Asian Society of Human Services

$\begin{array}{ll}\text { Editor-in-Chief } & \text { Masahiro KOHZUKI } \\ \text { Presidents } & \text { Masahiro KOHZUKI } \cdot \text { Sunwoo LEE } \\ \text { Publisher } & \text { Asian Society of Human Services } \\ & \text { Faculty of Education, University of the Ryukyus, 1 Senbaru, Nishihara, Nakagami, Okinawa, Japan } \\ & \text { FAX: +81-098-895-8420 E-mail: ashs201091@gmail.com }\end{array}$

Production Asian Society of Human Services Press

Faculty of Education, University of the Ryukyus, 1 Senbaru, Nishihara, Nakagami, Okinawa, Japan FAX: +81-098-895-8420 E-mail: ashs201091@gmail.com 


\section{Asian Journal of Human Services \\ VOL.16 April 2019 \\ CONTENTS}

\section{ORIGINAL ARTICLES}

An Awareness Survey Involving Employees of Welfare Facilities for Older Persons to Develop an Education Program for Functional Recovery Care: Comparing Japan and South Korea

Kazutoshi FURUKAWA et al., 1

Development of a Draft Clinical Interpersonal Reactivity Index to Evaluate Empathy in Nurses

Yoshimi AOKI et al., 14

The Characteristics of Communication in Interprofessional Collaboration in Multidisciplinary Team

Miki ARAZOE, 29

Interprofessional Cooperation ICT Program Development aimed at "Nutrition Improvement"

Yuko FUJIO et al., 45

Study of "Individuality" on Nursing Care Job Construct of "Individuality" Perceived by Nursing Care

Workers: A Qualitative Interview Study

Kimiko YAMAMOTO et al., 58

The Development and Relevant Factors of a Self-Care Scale for Young Females with Dysmenorrhea

Eriko YAMAMOTO, 68

Investigating the Mediating Effect of Switching Barriers in the Relationship Between Social Service

Quality and Switching Intention

Sunhee KIM, 87

SHORT PAPERS

Global Trends in Developmental Disorders Education and Japan's Current Status and New Initiatives

Haruna TERUYA et al., 101

Consideration of Construct of the Education Curriculum Management Models for Health Impairment

Education in Japan: Focus on Career Education for Children with Chronic Diseases

Mitsuyo SHIMOJO et al., 112

REVIEW ARTICLE

I Review of Studies on Syntactic Development in Children and Adults with Intellectual and

Developmental Disorders: Comparing Japanese and International Studies

Manami KOIZUMI et al., 119

Published by

Asian Society of Human Services

Okinawa, Japan 